\title{
Lusotopie
}

Recherches politiques internationales sur les espaces issus de l'histoire et de la colonisation portugaises

$\mathrm{XIX}(1) \mid 2020$

Amílcar Cabral et l'idée de la révolution anticoloniale

\section{Amílcar Cabral e Pepetela: processos intertextuais a propósito do Homem Novo}

Amilcar Cabral and Pepetela: Intertextual Processes Concerning the New Man Amílcar Cabral et Pepetela. Processus intertextuels à propos de l'Homme

Nouveau

\section{Renata Flávia da Silva}

\section{(2) OpenEdition Journals}

\section{Edição electrónica}

URL: https://journals.openedition.org/lusotopie/4744

ISSN: 1768-3084

\section{Editora}

Idemec - UMR 7307

\section{Edição impressa}

Data de publição: 4 agosto 2020

Paginação: 101-114

ISSN: 1257-0273

\section{Refêrencia eletrónica}

Renata Flávia da Silva, «Amílcar Cabral e Pepetela: processos intertextuais a propósito do Homem Novo», Lusotopie [Online], XIX(1) | 2020, posto online no dia 02 janeiro 2022, consultado o 04 fevereiro 2022. URL: http://journals.openedition.org/lusotopie/4744

Este documento foi criado de forma automática no dia 4 fevereiro 2022

Lusotopie 


\section{Amílcar Cabral e Pepetela: processos intertextuais a propósito do Homem Novo}

Amilcar Cabral and Pepetela: Intertextual Processes Concerning the New Man Amílcar Cabral et Pepetela. Processus intertextuels à propos de l'Homme

Nouveau

Renata Flávia da Silva

A África de todos os dias, oh! não a dos poetas, não a que adormece, mas a que não deixa dormir, porque o povo está impaciente por fazer, actuar, dizer. O povo que diz: quero construir-me como povo, quero edificar, amar, respeitar, criar. Este povo que chora quando dizeis: venho de um país onde as mulheres não têm filhos e os filhos não têm mães [...]. Era pois a África [...]. Esta África que tínhamos de orientar, mobilizar, lançar na ofensiva. Esta África futura. Fanon 1980: 215

Mas nós resolvemos fazer das nossas cabeças aquela semente que se põe na terra para fazer nascer novas plantas. Claro que pode acontecer algum desastre. [...] A resistência dum povo, exige coragem para nos transformarmos em semente para criar uma nova plantação que dará então a felicidade desse povo, na liberdade.

Cabral 1979: 8

1 Há seis décadas, Frantz Fanon evocava a imagem de um África futura, descolonizada, ao defender o direito das nações africanas à emancipação. Uma África que se forjava com 
amor, entusiasmo, mas, também, com força e violência. De igual modo, Amílcar Cabral fomentava, anos depois, uma África a germinar, nova e liberta, a partir das sementes plantadas na luta anti-colonial. É esta África futura, representada literariamente na figura da criança, um "Homem Novo" em formação, o tema a ser discutido no presente artigo.

2 Para tal, objetiva-se considerar duas obras do escritor angolano Pepetela: a novela As aventuras de Ngunga, escrita em 1972 e publicada em 1976, e o romance Se o passado não tivesse asas, publicado em 2016. Esta investigação motiva-se pelo desejo de averiguar as diferentes representações infantis do futuro homem angolano, inspirado nos ideais revolucionários propagados por Cabral, tendo em vista não só o distanciamento temporal entre as obras aqui destacadas, mas também as transformações sofridas pela sociedade angolana nas últimas quatro décadas.

3 Empenhados em realizar uma releitura do discurso revolucionário de Amílcar Cabral, sobretudo no que tange à formação de um Homem Novo africano - visto como uma construção identitária necessária à libertação e consolidação das nações africanas independentes do jugo colonial -, optamos por discutir os processos de construção literária ficcional de Pepetela a partir de suas afinidades com o legado teórico de Cabral, ou seja, da utilização de parte de uma estratégia política como estratégia narratológica de um escritor também revolucionário, pois participante das lutas de libertação em Angola, em diferentes momentos de sua carreira literária.

4 A fim de fundamentarmos a nossa verificação das estratégias de naturalização das diferenças em uma política de representação pautada pela uniformização dos futuros cidadãos descolonizados, bem como da criação de uma imagem estereotipada do "inimigo" da nação a ser combatido, tomaremos por base o trabalho de Stuart Hall acerca da representação do negro ao longo dos processos históricos, em Cultura e representação (2016). Já para observarmos as relações dialógicas entre os textos de Cabral e as obras literárias de Pepetela, isto é, a transposição de um "arquivo indefinido", composto pelas ideias e formulações teóricas de Cabral acerca da luta anticolonial, para um universo literário alicerçado na problematização da história angolana, tomaremos por base o conceito de adaptação, desenvolvido por Linda Hutcheon, em Uma teoria da adaptação (2013), objetivando constatar as permanências e/ ou as rupturas dos discursos anticoloniais de Cabral nas obras ficcionais de Pepetela.

Para Cabral, os indivíduos ideais à nova sociedade que se pretendia formar deveriam passar por uma transformação cultural, étnica e linguística, a fim de constituírem um só povo, formado por homens educados, treinados e formados moralmente para a coletividade em detrimento de seus anseios individuais. Desde os anos 40 , o jovem líder refletia acerca da formação de um Homem Novo, constituído em sua base tanto pelas camadas assimiladas da população africana colonizada quanto pelas massas populares, ainda próximas à cultura tradicional de seus países (Cabral 1947: 24-25). Também em sua intervenção na Conferência Tricontinental de Havana, em 1966, Cabral elogiava o êxito da revolução cubana "que, nos campos e nas cidades, esta[va] criando não só uma vida nova, mas também - o que [era] mais importante - um Homem Novo, plenamente consciente dos seus direitos e deveres nacionais, continentais e internacionais" (Comitini 1980: 22).

6 Havia, no pensamento de Cabral, a preocupação com a formação dos futuros cidadãos livres da Guiné-Bissau e de Cabo Verde. Era preciso cultivar, qual a semente indicada aqui em epígrafe, o sentido da coletividade e do bem-estar comum acima das diferenças 
culturais existentes e acima dos valores trazidos pela colonização, ainda que este direcionamento não fosse o desejado por todos os envolvidos:

O nosso objetivo é rebentar com o estado colonial na nossa terra para criarmos um estado novo, diferente, na base da justiça, do trabalho e da igualdade de oportunidade para todos os filhos da nossa terra, na Guiné e em Cabo Verde.

Queremos, portanto, destruir tudo quanto seja um obstáculo ao progresso do nosso povo, todas as relações que há na nossa sociedade, na Guiné ou em Cabo Verde, que sejam contra o progresso do nosso povo, contra a liberdade do nosso povo. [...] Passo a passo, um a um se for preciso, mas temos que destruir para construir uma vida nova. Este é que é o objetivo principal da nossa resistência.

Cabral 1979: 10-11

7 A destruição necessária para a construção da nova nação acarretaria, muitas vezes, o silenciamento e a exclusão daqueles contrários aos modelos político-sociais estabelecidos pelos movimentos de libertação. Tal pensamento alicerçou as ações de vários grupos contra o colonialismo português. Aliada à componente militar das diferentes frentes de combate, a estratégia cultural de desalienação e conscientização política constituiu importante vetor de resistência, propaganda e engajamento. Para Cabral, era necessário

[...] trabalhar muito para liquidar na nossa cabeça a cultura colonial, camaradas. $\mathrm{E}$ queiramos ou não, na cidade ou no mato, o colonialismo meteu-nos muitas coisas na cabeça. E o nosso trabalho deve ser tirar aquilo que não presta e deixar aquilo que é bom. Porque o colonialismo não tem só coisas que não prestam. Devemos ser capazes, portanto, de combater a cultura colonial e deixar na nossa cabeça aquele aspecto de cultura humana, científica, que porventura os tugas trouxeram para a nossa terra e entrou na nossa cabeça também.

Ibid.: 72

8 Esse trabalho de formação foi assumido também pelas frentes de combate em muitas ocasiões e em diferentes regiões do continente. Reverberando as palavras de Cabral, em 1972, na Frente Leste, o jovem Artur Carlos Maurício Pestana dos Santos, guerrilheiro do Movimento Popular de Libertação de Angola (MPLA), conhecido por Pepetela (pestana em umbundo), diante da necessidade de alfabetizar os jovens soldados e também difundir os ideais revolucionários que alimentavam a luta, escreve As aventuras de Ngunga (1972). A narrativa curta trazia em seu protagonista a representação ideal deste novo homem angolano, dotado da consciência revolucionária necessária à conquista da libertação, unindo assim a ideologização da guerra ao seu cotidiano nos pequenos agrupamentos guerrilheiros. A imagem do jovem guerrilheiro corresponderia, assim, aos propósitos de uma política de representação pautada pela uniformização dos indivíduos, reproduzindo as bases dicotômicas da nação colonizada nas figuras do revolucionário e de seus opositores.

Pepetela, angolano nascido em Benguela no ano de 1941, é hoje um dos grandes expoentes da literatura em língua portuguesa. Sociólogo de formação, escritor há cinco décadas, foi também, como dissemos acima, um combatente na luta pela libertação de Angola. Sua trajetória como guerrilheiro e intelectual, partícipe do projeto de construção da nação livre, faz-no aproximar suas produções literárias dos discursos teóricos do líder cabo-verdiano, assim como nos leva a investigar as permanências e transformações verificadas em sua obra ao longo dos anos no que diz respeito à representação da nação descolonizada.

Dada a extensão da sua produção literária - a qual compreende novelas, romances, contos e crônicas, além de uma peça de teatro - e o foco ajustado para o conceito 
utópico de Homem Novo defendido por Cabral, optamos por restringir nossas análises a duas obras especificamente, As aventuras de Ngunga (1972) e Se o passado não tivesse asas, (2016), embora outras obras do autor possam figurar como reforço analítico. Quatro décadas separam as duas narrativas. Entretanto, em ambas vemos refletidas as palavras de ordem de Cabral, ainda que (re)lidas em outros contextos e travestidas de diferentes simbologias; vemos a África futura, trazida aqui epigraficamente pelas palavras de Fanon, representada na criança angolana, nos muitos órfãos de guerra, filhos sem mãe e, ainda assim, promessas de um futuro, de homens e mulheres novos.

O mais maravilhoso o mais delicado que há no mundo, são as crianças. Às crianças devemos dar o melhor que temos. Devemos educá-las para se levantarem com o espírito aberto, para entenderem as coisas, para serem boas, boas, para evitarem toda a espécie de maldade. Portanto, nunca devemos fazer-lhes mal algum, quanto mais matá-las.

Cabral 1979: 72

11 Antes d'As aventuras de Ngunga, Pepetela já havia dado à criança o protagonismo e o desejo de ação no conto "Revelação", escrito em 1962. Neste conto, o pequeno Candimba, um menino "pequeno e fraco, uma criança [...] a que ninguém sequer prestava atenção" (Pepetela 2008: 29), torna-se capaz de matar inesperadamente um indefeso animal de estimação, motivado pela frustração e pela revolta contra o sistema colonial que o anulava e o reduzia a um lugar de testemunha sem voz, sem valor. Candimba avança contra o animal na impossibilidade de agir contra o seu opressor.

12 Essa tomada de posição diante do colonizador, representada na criança que desfere contra o coelho branco a revolta sentida, é potencializada na novela As aventuras de Ngunga, dez anos mais tarde. Ao longo de 29 capítulos curtos, temos o percurso de amadurecimento do pequeno órfão de 13 anos durante os conflitos da guerra de libertação. Ngunga perde os pais em um ataque do exército português e é levado a viver junto dos guerrilheiros. Durante sua busca por um mundo novo, descobre a maldade, a ganância, as limitações da tradição, mas também conhece o valor da educação, da amizade, da coragem e do amor. O jovem passa de criança a guerrilheiro, mantendo-se firme e fiel aos ideais revolucionários, obedecendo, assim, à política de representação em voga no período.

Ngunga, órfão, 13 anos, um dentre tantos deslocados de guerra, o personagem infantil talvez mais famoso de Pepetela, encarna a projeção utópica deste novo homem africano, que não nasceria na cidade, viria do mato - como na canção de Zeca Afonso ${ }^{1}$ anos mais tarde -, parte essencial do projeto de construção da nação. A emblemática figura do jovem Ngunga, pioneiro exemplar, leal e corajoso, apresenta-se como modelo de conduta a ser seguido. $O$ jovem pioneiro, apesar de todas as adversidades causadas pela dominação colonial e também por tradições das quais discordava, não perde a convicção de ser um guerrilheiro e lutar pelo fim da opressão, ainda que isso significasse a supressão de desejos e sentimentos em prol do bem comum, como podemos observar na cena em que decide abandonar seu amor para voltar à escola: "Mais uma vez Ngunga jurou que tinha de mudar o Mundo. Mesmo que, para isso, tivesse de abandonar tudo do que gostava" (Pepetela 1987: 54). Não há espaço, na narrativa, para quaisquer questionamentos acerca da homogeneização da sociedade angolana em favor da sua libertação. Mais uma vez, vê-se a destruição necessária à construção da nação sendo valorizada e difundida. 
Para os líderes do movimento de libertação, uma atitude compreensível e desejável diante da difícil tarefa de construir a unidade nacional em meio às diferenças culturais e políticas presentes no terreno. Kelly Araújo atesta que

[f]alar em política cultural em Angola [antes e] após a independência é também falar das estratégias utilizadas pelos representantes do nascente Estado na construção da nacionalidade, ou do sentimento de pertença a um projecto de nação, aqui entendido como um 'tipo muito nítido de sentimento e sensibilidade de lealdade e identificação', por aqueles que faziam parte, dentro dos limites territoriais definidos, deste mesmo Estado.

Araújo 2009: S/P

Essas mesmas estratégias, capazes de infundir lealdade e identificação, eram utilizadas também por escritores como Pepetela, imbuídos não só de um ideal, mas também de uma "missão": difundir, através do texto literário, a representação do novo homem angolano. Ainda citando Araújo,

[e]ste homem angolano é, na verdade, um novo homem angolano, adequado aos princípios adoptados pelo Estado. Este novo homem deveria ser o fio condutor para o estabelecimento de uma nova sociedade, assentada em novos propósitos: não poderia ser um homem 'reaccionário', entendido aqui como tendo enraizado as suas particularidades étnicas ou regionais; nem mesmo ser um assimilado, produto da política colonial. Através deste novo homem é que se esperava encontrar a unidade nacional.

Ibid.

16 Nada melhor, portanto, que a figura da criança, com toda a potencialidade de um futuro ainda em formação para representar esse Homem Novo ideal. Ao final d'As aventuras..., após Ngunga ter assumido seu lugar na luta pela libertação do país e ter-se tornado mais um combatente anônimo, o narrador dirige-se diretamente a seu interlocutor, o "camarada pioneiro", a fim de reforçar valores e atitudes deste Homem Novo: "[...] talvez Ngunga tivesse um poder misterioso e esteja agora em todos nós, nós que nos recusamos viver no arame farpado, nós que recusamos o mundo dos patrões e dos criados, nós os que queremos o mel para todos" (Pepetela 1987: 59), reafirmando a identificação necessária com o projeto de construção nacional tal qual moldado por seus dirigentes.

17 Lembrando, mais uma vez, as transposições textuais aqui defendidas, aproximamos a figura do jovem órfão, filho de todos, construído por Pepetela, do ideário revolucionário de Cabral,

Devemos convencer o nosso povo, pelos nossos gestos, pela nossa aç̧ão, pelas nossas palavras, de que os nossos soldados, os nossos combatentes, são seus filhos, que lutam para o defender, que saíram do seu peito, da sua barriga, para o defender, não para lhe fazer mal.

Cabral 1979: 132

18 Apoiando-nos nos estudos de Hall, podemos dizer que esta imagem dos "filhos da nação" atende a um regime de representação dotado do poder de atribuir, classificar e excluir alguém ou alguma coisa, segundo seus próprios critérios, exercendo uma violência simbólica aliada, quase sempre, a uma violência física imposta por quem o detém, contribuindo, assim, para a permanência de uma violência atmosférica presente não só durante o período colonial, mas também após seu fim.

19 Ao longo de sua produção literária, Pepetela vem reelaborando, em várias obras, tal representação metonímica da nação, o novo homem forjado na luta. Contudo, ao fazê-lo em obras mais distanciadas dos anos 70, outra ênfase é dada ao futuro em construção. 
As palavras de ordem de Cabral não se perderam nessa travessia; ecoam ainda em personagens representativas não mais da coragem e lealdade do guerrilheiro, mas da grande luta do outrora revolucionário e hoje parte integrante da elite nacional: a luta contra as suas próprias fraquezas. "Trair a revolução ou suicidar-se como classe" (Comitini 1980: 41) pode ser uma das representações da Angola independente. Ao contrário do mundo ansiado por Ngunga, a reorganização da sociedade angolana, após a sua independência, propiciou a formação de um mundo intervalar, dotado de inúmeras possibilidades de representação, em diferentes nuances de adesão ou exclusão ao modelo de "cidadão angolano" proposto anteriormente.

Uma das tônicas dos discursos de Cabral era, sem dúvida, a necessidade de fomentar e sustentar a Unidade e a Luta, tanto que ambas se tornam as palavras de ordem do Partido. A unidade, de todos em prol do bem comum, e a luta, interna contra os desvios de conduta, quer seja do povo dividido entre os ideais revolucionários e as melhorias concretas desejadas, quer seja da classe dirigente que ocupará os lugares deixados pelo colonizador. Para Cabral,

[e]videntemente, tanto a eficácia dessa via como a estabilidade da situação a que ela conduz, depois da libertação, dependem não só das características da organização da luta, mas também da consciência política e moral daqueles que, por razões históricas, estão em condições de ser os herdeiros imediatos do Estado colonial ou neocolonial. Ora os fatos têm demonstrado que a única camada social capaz, tanto de consciencializar em primeiro lugar a realidade da dominação imperialista, como de manipular o aparelho do Estado, herdado dessa dominação, é a pequena burguesia nativa. Se tivermos em conta as características aleatórias, a complexidade $\mathrm{e}$ as tendências naturais inerentes à situação económica dessa camada social ou classe, vemos que esta fatalidade específica da nossa situação é mais uma das fraquezas do movimento de libertação nacional.

Ibid.: 39

21 Tais questionamentos estão presentes, também, nas palavras de Fanon: “[o]ntem filhos mimados do colonialismo, hoje da autoridade nacional, organizam a pilhagem de alguns recursos nacionais. Impiedosos, sobem na vida através de negociatas ou roubos legais [...] nessa miséria hoje nacional" (Fanon 1980: 65). Os caminhos futuros da revolução poderiam tomar rumos não desejados.

Voltando à produção literária de Pepetela, destacamos, agora, a narrativa de Se o passado não tivesse asas (2016). Neste romance, o autor explora dois momentos históricos distintos: o primeiro, 1995, período ainda de conflitos civis em Angola, e o segundo, 2012, a primeira década em paz após o cessar fogo de 2002. Os dois tempos distintos pertencem a duas trajetórias, inicialmente distintas, que acabam por se unir no final. Himba/Sofia, os dois nomes que a protagonista recebe ao longo da narrativa é, agora, o novo homem angolano em análise.

Porém, antes de avançarmos, convém fazermos um breve apontamento. Há entre o romance publicado em 2016 e a crônica intitulada "Meninos de rua", publicada originalmente em 1994, uma relação intertextual. Pepetela recupera a história narrada nos anos 90 e a desenvolve em forma romanesca, acrescentando uma segunda parte à narrativa, o futuro daqueles meninos e meninas das ruas de Luanda. Não analisaremos aqui o procedimento de transposição extensiva de uma obra para a outra, incluindo uma mudança de gênero textual, utilizada pelo autor, pois já o fizemos em outra ocasião (Silva 2018: 215228). Porém, achamos necessário frisar que a história narrada em 2016 envolve um deslocamento na representação cultural inicial, da crônica, a 
partir do acréscimo de um futuro à infância retratada, futuro este marcado por acontecimentos decorridos nos últimos vinte anos em Angola.

O recurso utilizado por Pepetela para esta reinterpretação criativa da crônica é a junção de duas histórias que seguem em paralelo em uma única história, dividida em tempos distintos, como já dissemos: a de Himba, o tempo da infância, da guerra, da violação, da fome, dos anos 90 em Luanda; e de Sofia, a fase adulta, do pós-guerra, do crescimento profissional, das novas amizades, da segunda década do século XXI. Tal qual o jovem Ngunga, a pequena Himba é também uma órfã de guerra; deslocada de seu espaço original, vai para Luanda sozinha em busca de parentes que pudessem acolhê-la. Sem encontrar nenhum familiar, passa a viver nas ruas da capital, sempre ao lado do pequeno Kassule, também uma criança abandonada nas ruas de Luanda. Mutilado pela guerra, o jovem se torna o principal apoio de Himba. Já Sofia, uma jovem gerente de um restaurante frequentado pela elite luandense, é ela o apoio do irmão pintor, Diego, demonstrando iniciativa e vontade de vencer na vida.

Himba (que depois mudará por vontade própria seu nome para Sofia) representa imagens de uma infância que precisa ser lida no contexto de outras imagens, pois seu "significado depende da diferença entre os opostos" (Hall 2016: 154), como nos aponta Hall, entre o heroísmo de Ngunga e os novos valores de Sofia.

Sofia causa um estranhamento no leitor habituado aos valores revolucionários e heroicos, já retratados por Pepetela, por não caber nas identificações até então existentes; sua ambivalência extrapola os limites simbólicos de uma infância fragilizada ou heroica. Pepetela, ao nos trazer a fase adulta da pequena e frágil criança, desnaturaliza sua vitimização. Para Stuart Hall, "[a] 'naturalização' é, portanto, uma estratégia representacional que visa fixar a diferença e, assim, ancorá-la" para sempre. É uma tentativa de deter o inevitável "deslizar" do significado para assegurar o "fechamento" discursivo ou "ideológico" (Ibid.: 171). Deste modo, ao permitir que a personagem cresça, ao contrário das narrativas citadas anteriormente, e ambicione novas posições na sociedade em que vive, Pepetela abre novas perspectivas de representação da sociedade angolana, menos polarizadas, mais fluídas, onde os limites simbólicos outrora estabelecidos se encontram, agora, numa zona híbrida. o desejado modelo revolucionário, eco das palavras de Cabral, não é mais tão bem definido. Da fixidez dos significados atribuídos à representação do novo homem angolano em As aventuras de Ngunga atinge-se a flutuação de significados possíveis em Se o passado não tivesse asas, já que Himba/Sofia flutua entre os polos positivo e negativo da representação. Himba representa, ao mesmo tempo, as vítimas e os herdeiros dessa Angola conturbada.

27 Cabral já alertava, em A arma da teoria, para a fragilidade das conquistas diante das incertezas após a libertação, como já o dissemos aqui. Também o historiador francês Yves Benot destaca ser a classe de dirigentes políticos

[...] esta classe, que não tem bases econômicas, uma vez conquistada a independência, encontra-se numa encruzilhada: pode ceder ao aburguesamento, e então não lhe resta outra saída senão a aceitação do neocolonialismo.

Benot 1969: 426

Sofia transita entre os jovens membros desta "casta burocrática e arranjista, instrumento ad hoc do neocolonialismo" (Ibid.: 429), para usarmos ainda as palavras de Benot, e, embora, não se deslumbre com o mundo que se abre a ela através dos "príncipes" que frequentam seu restaurante, assume atitudes discutíveis se 
confrontadas com a representação do Homem Novo defendida tanto por Cabral quanto pelo próprio Pepetela em anos idos. Sofia seduz, ameaça, mata, apossa-se da propriedade alheia, enfim, sobrevive com as armas que dispõe diante do estado permanente de violência em que se encontra.

Na figura de Sofia, temos uma acumulação de significados que se dá, sobretudo, se lidos dialogicamente com outros textos do autor, como As aventuras de Ngunga (1976), Mayombe (1980) ou Predadores (2005), por exemplo. A representação da infância na literatura angolana esteve, durante muito tempo, semanticamente ligada a uma ideia de futuro, um promissor vir a ser, livre, independente, justo, tal qual defendido desde os teóricos marxistas inspiradores de Cabral. Para a teórica canadense Linda Hutcheon, em Uma teoria da adaptação, "o contexto condiciona o significado" (Hutcheon 2013: 196), ou seja, as mudanças trazidas com as últimas décadas em Angola, os conflitos civis, a crise política, ressemantizam as associações estabelecidas e forçam a alteração na trajetória da personagem, da sua infância à vida adulta.

Voltando às palavras de Cabral, entre "trair a revolução ou suicidar-se como classe" (embora saibamos que a personagem não pertence exatamente à nova burguesia angolana, mas almeja ter as mesmas melhorias concretas que essa classe tem), a escolha de Sofia é pelo apagamento total do passado, sua história de vida, seu nome e a adoção de novos valores. Entretanto, seu corpo tantas vezes violentado pela fome, pela exploração sexual, pelo abandono ocasionado pelos conflitos civis, revela-se um lugar de memória indelével. Ao ser questionada pelo irmão após confessar ter-se apossado da propriedade a qual gerenciava, Sofia responde: “ - Eu sou o que fizeram de mim. 0 teu país" (Pepetela 2016: 371). A complexidade da personagem, ora vítima, ora algoz, é representativa de outra complexidade, a das memórias individuais, tal qual a da jovem, inseridas numa rede de interações sociais marcadas pelos processos de colonização e de descolonização.

31 Nesse jogo de culpas e desacertos, as sábias palavras do jovem Kassule/ Diego, também vítima da guerra fratricida angolana, tentam reorganizar os papéis deslocados pelas atitudes de Sofia, " - Outros sofreram como tu e continuaram honestos e dignos. Humanos... O país é de todos e não deve ser culpado pelos erros dos seus filhos" (Ibid.: 371). A Unidade da nação e a Luta para não sucumbir aos desvios permanecem presentes na concepção do jovem.

32 As imagens dessa nova geração de angolanos que sobreviveu ao caótico cotidiano das guerras continua em aberto: de uma política de representação, que tinha no Homem Novo o modelo a ser veiculado, passamos a uma representação política, porque crítica, do homem/mulher angolanos, ambíguos e moventes. A narrativa se encerra com um ponto de interrogação. Sofia se pergunta, relembrando as palavras ditas pelo irmão: “(...) é este o nosso futuro, a ditadura da ganância"? (Ibid.: 372). Teriam os filhos da guerra, os jovens Ngungas, deslizado em sucessivas representações, atingido o polo oposto do Homem Novo africano? Teriam as palavras de Cabral sido superadas pelos novos discursos neocoloniais?

33 A complexidade das trajetórias das personagens, Himba/Sofia, Kassule/ Diego, torna o significado de termos como infância, passado ou futuro relacional, fazendo-nos experienciar de maneira duplicada a apreensão da representação destas infâncias e juventudes. Ao lado de Sofia temos Diego. O jovem pintor permanece combativo e solidário. Apesar das benesses proporcionadas por sua irmã afetiva, permanece em comunhão com ideais e valores caros a um projeto humanista como o do Homem Novo. 
Em um jogo de permanências e rupturas dos ideais revolucionários, Pepetela reelabora o futuro da nação, alegoricamente representado nas figuras de Sofia e Diego.

Para a pesquisadora Inocência Mata, a "irrealização do projeto utópico" (Mata 1993: 283) de uma Angola ideal, mais justa, mais fraterna, dá lugar a uma nova utopia representada pela ideia de um país adiado. Este estado de suspensão é textualmente representado na narrativa de Pepetela pela interrogação final.

Pensar em tais representações, quer do Homem Novo africano, quer dos jovens personagens, enquanto fenômenos culturais contingenciados temporal e espacialmente, leva-nos a considerar tanto o discurso teórico de Cabral quanto o discurso literário de Pepetela como discursos inegavelmente históricos. A história dos processos de libertação das colônias portuguesas em África, a qual inclui o legado teórico de Cabral, passa a ser um arquivo discursivo ao qual a ficção recorre para problematizar os caminhos trilhados após a libertação.

De igual modo, pensar na ampliação do regime de representação da nação a fim de incluir novos papéis sociais, além das figuras do revolucionário e do Homem Novo (alguns até indesejáveis), é também pensar na interação dos discursos de Cabral e da ficção produzida em países como Angola e na persistência de um ideal de libertação e construção de uma nova sociedade ainda não alcançada. A pergunta permanece sem resposta: “(...) é este o nosso futuro, a ditadura da ganância”? (Pepetela 2016: 372). À África futura.

\section{BIBLIOGRAFIA}

Araújo, K. C. O. 2009, “'Um só povo. Uma só nação.' O Estado e a diversidade cultural em Angola (1975-1979)", União dos Escritores Angolanos, http://www.ueangola.com/criticas-e-ensaios.

Araújo, M. P. N \& M. Santos 2007, "História, memória e esquecimento: implicações políticas", Revista Crítica de Ciências Sociais, 79: 95-111.

Benoit, Y. 1969, Ideologias das independências africanas, Lisboa, Sá da Costa / Luanda, INALD.

Cabral, A. 1947, “A propósito da educação”, Boletim de Propaganda e Informação, 21: 24-25.

Cabral, A. 1979, Análise de alguns tipos de resistência, Bolama, Imprensa Nacional da Guiné-Bissau.

Comitini, C. ed. 1980, Amilcar Cabral. A arma da teoria, Rio de Janeiro, CODECRI.

Cury, M. Z. F. 2013, "Poéticas da precariedade", Estudos de Literatura Brasileira Contemporânea, 41: 33-45. DOI: https://doi.org/10.1590/S2316-40182013000100003.

Fanon, F. 1980, Em defesa da Revolução Africana, Lisboa, Livraria Sá da Costa.

Hall, S. 2016, Cultura e representação, Rio de Janeiro, Editora PUC-Rio/Apicuri.

Hutcheon, L. 1991, A poética do pós-modernismo, Rio de Janeiro, Imago.

Hutcheon, L. 2013, Uma teoria da adaptação, Florianópolis, Editora da Universidade Federal de Santa Catarina. 
Mata, I. 1993, Ficção e história na literatura angolana: o caso de Pepetela, Lisboa, Edições Colibri.

Mata, I. 2010, Ficção e história: o caso Pepetela, Lisboa, Edições Colibri.

Pepetela 1982, Mayombe, São Paulo, Ática.

Pepetela 1987, As aventuras de Ngunga, São Paulo, Ática.

Pepetela 2005, Predadores, Lisboa, Dom Quixote.

Pepetela 2008, Contos de morte, Lisboa, Edições Nelson de Matos.

Pepetela 2011, Crônicas com fundo de guerra, Lisboa, Edições Nelson de Matos.

Pepetela 2016, Se o passado não tivesse asas, Alfragide, Dom Quixote.

Pureza, J. M. 2013, “A turbulência das zonas de fronteira: estereótipos, representações e violências reais”, in A. S. Ribeiro ed., Representações da violência, Coimbra, Almedina.

Schurmans, F. 2014, O trágico do estado pós-colonial: Pius Ngandu Nkashama, Sony Labou Tansi, Pepetela, Coimbra, Almedina.

Silva, R. F. 2018, "Meninos da rua: Pepetela e a reescritura do passado", De Oriente a Ocidente estudos da AIL sobre África, III: 215-228, Disponível em https://lusitanistasail.press/index.php/ ailpress/catalog/book/165.

\section{NOTAS}

1. Cf. Um homem novo veio da mata, canção do álbum Enquanto há força, de 1978.

2. A crônica "Meninos de rua" foi publicada, originalmente, no Jornal O Público, em 1994, e reunida mais tarde, em 2011, no volume Crônica com fundo de guerra, editado pelas Edições Nelson de Matos.

\section{RESUMOS}

O artigo analisa a representação ficcional do Homem Novo a partir das obras As aventuras de Ngunga (1976) e Se o passado não tivesse asas (2016), do escritor angolano Pepetela, relacionando-as ao legado teórico de Amílcar Cabral. Tendo em vista os discursos deixados por Cabral, investigase sua permanência e/ou ruptura nos textos literários. Para tal análise, corroboram, além dos textos de Cabral, os estudos de representação cultural de Stuart Hall e as formulações acerca dos processos de adaptação textuais defendidas por Linda Hutcheon.

The article analyzes the fictional representation of the New Man in the works As aventuras de Ngunga (1976) and Se o passado não tivesse asas (2016), by the Angolan writer Pepetela, relating them to the theoretical legacy of Amílcar Cabral. In view of the discourses left by Cabral, its permanence and/or rupture in the literary texts is investigated. For such analysis, besides the texts of Cabral, the article uses the studies of cultural representation of Stuart Hall and the formulations about textual adaptation processes defended by Linda Hutcheon. 
L'article analyse la représentation fictionnelle de l'Homme Nouveau dans les œuvres As aventuras de Ngunga (1976) et Se o passado não tivesse asas (2016), de l'écrivain angolais Pepetela, en le reliant à l'héritage théorique d'Amílcar Cabral. Nous analysons les ruptures et les permanences de l'apparition de la figure de l'Homme Nouveau dans ces textes au regard des textes laissés par Cabral. L'article mobilise les études des représentations culturelles de Stuart Hall et le cadre des processus d'adaptation textuelle défendu par Linda Hutcheon.

\section{ÍNDICE}

Mots-clés: Amílcar Cabral, Pepetela, Homme Nouveau, intertextualité, fiction

Palavras-chave: Amílcar Cabral, Pepetela, Homem Novo, intertextualidade, ficção

Keywords: Amílcar Cabral, Pepetela, New Man, intertextuality, fiction

\section{AUTOR}

\section{RENATA FLÁVIA DA SILVA}

Instituto de Letras, Departamento de Letras Clássicas e Vernáculas, Universidade Federal

Fluminense, Brasil

renataflaviadasilva[at]gmail.com 